\title{
Dr. APPOINTMENT AND COMMUNICATION ANDROID APPLICATION
}

\author{
Satyam Singh*1 and Rahul Kumar ${ }^{2}$
}

1,2Department of Information Technology, IMS Engineering College, Ghaziabad, U.P., India

\section{A R T I C L E I N F O}

\section{Article History:}

Received $16^{\text {th }}$ December, 2016

Received in revised form $16^{\text {th }}$ January, 2017

Accepted $26^{\text {th }}$ February, 2017

Published online $28^{\text {th }}$ March, 2017

\section{Key words:}

Android online appointment, doctor-patient interaction, online medical record

\begin{abstract}
A B S T R A C T
In today's generation if anyone wants to book a Dr Appointment we need to call in health centre or personally go to that place and book the appointment on particular date. This consumes important time of the patient. Also if the doctor drop his/her schedule, the patient does not come to know about it unless he/she goes to the health centre. The aim of this project is to build a android base system that will ease the process of booking appointment of the doctor. The patient will book the appointment through his/her mobile phone any time. The doctor will come to know the number of patients he has to attend whole day. The system will save patient's as well as doctor's time. It will save the receptionist's paper work. The system will prove to be useful for doctor as he can check his appointments whenever and from wherever he wants from his mobile phone. All medical record does not carry with $\mathrm{him} / \mathrm{her}$, online report generate and save online.
\end{abstract}

Copyright $(2017$ Satyam Singh and Rahul Kumarl. This is an open access article distributed under the Creative Commons Attribution License, which permits unrestricted use, distribution, and reproduction in any medium, provided the original work is properly cited.

\section{INTRODUCTION}

In this fast driven society, where the current, where the current climate in the healthcare sector demands efficiency and patient's satisfaction in medical care delivery. The number of missed appointments, unnecessary waste of patient time. Making appointments over the mobile phone provides more benefits. These include time saving as staff spends less time in attending patients compared to paper-based appointments where patients need to fill in lots of forms

The establishment and improvement of doctor-patient interaction system is a very important requirement, especially now when the mobile generation is developing rapidly. Furthermore, the automated appointment reminder in the mobile appointment scheduling system the advantages of mobile web can be made full use of to make up the time and distance gapbetween doctors and patients and to provide fast and adequate medical services. Mobile phone based appointment system allows for 24 hours convenient scheduling and patients can make appointments at any time compared to making alert on the upcoming appointment. Through the connection between m o b i l e terminals and specific service, both doctors and patients are able to obtain required data to achieve a better dealing. The platform, Web services and database technology are all gradually maturing, so that we can develop a doctor-patient interaction system on android platform to meet the needs of the patient and provide

*Corresponding author: Satyam Singh

Department of Information Technology, IMS Engineering College, Ghaziabad, U.P., India doctors more efficient and convenient means of communication with patients. Patient side unnecessary document does not carry with him there is also medical record save.This study's objective is to enhance the appointment scheduling system via a mobile application, which facilitates assigning time slots to patients whenever they make appointments and prioritize patients with high precedence. Patients who forget their appointments can receive a reminder International Journal of Computer Science and Information Security (IJCSIS), Vol. 13, No. 11, November 201521 https://sites.google.com/site/ijcsis/ ISSN 1947-5500 alert on the upcoming appointment, and the clinic can track appointments and health performance of their patients.

\section{LITERATURE SURVEY}

Here we present a doctor-patient interaction system based on Android. Appointment scheduling via paper-based system requires patients to be at the hospital, fill in registration forms and return them to the registration desk, and patients are then assigned to the desired doctor. This application drop out all this unnecessary things during appointment. Its excellent performance on mobile terminals makes it possible that atients are able to access the hospital server to obtain the nec essary suggestion about the symptoms and interact with the doctors on their own mobile terminals, while doctors can track patients whenever and wherever possible or make a diagnosis of alert depends on the monitoring data from the hardware of mobile terminals. Paper describes the needful things that the Doctor has to do every day. In this paper, we solve this problem by proposing a new system based on android technology, through that the doctor can manage his/her appointments from anywhere. In addition to this the patient who is unable to go feasibility study is major 
factor which contributes to analysis of system. To the health centre and take the appointment can also book his/her appointment from a mobile phone within 2-3 min. Our solution is to build a system that will help the needful people or every person who wants to save their precious time. Appointment scheduling via paper-based system requires patients to be at the hospital, fill in registration forms and return them to the registration desk, and patients are then assigned to the desired doctor. Sometimes, patients place hospital identification cards or appointment cards in the dedicated box near the doctor's room, and then wait in the queue to be called by the nurse. Cards are placed in the order of first come, first serve (FCFS), whereby the patient who came early is the first to be served and the last to show up waits on the queue. Patient information in the paperbased appointment system cannot be easily corrected when changes need to be made: another form will need to be filled in, and the data entry registration desk staff experience problems in reading information written in the paper appointment forms, and it is difficult to retrieve patient details when required as you need the entire appointment application form This type of appointment scheduling system has a range of constraints, such as patients being required to fill in appointment forms upon arrival at the hospital, and there is no possibility to register while at home or any place as a result, patients spend a lot of time waiting in queues, are required to follow dates of appointment assigned by the registration desk, and there is no mechanism for patients notification when appointments are postponed. Additional, managing paperbased hospital appointment system is difficult to manage, hence the need for a new method. The use of mobile appointment scheduling can enhance hospital appointments as it will allow patients to make appointments before going to the hospital. Patients can be reminded of the appointment as well. The clinic can monitor patient's performance while on the provided treatment, and the patient can select desired date of appointment based on his/her wishes.

\section{Feasibility Study}

The feasibility study is major factor which contributes to analysis of system. To the health centre and take the appointment can also book his/her appointment from a mobile phone within 2-3 min. Our solution is to build a system that will help the needful people or every person who wants to save their precious time.Appointment scheduling via paperbased system requires patients to be at the hospital, fill in registration forms and return them to the registration desk, and patients are then assigned to the desired doctor. Carried out to check workability of proposed system, so the feasibility study is system proposal regarding to its workability, impact on organization, ability to meet user requirements \& effective use of resources thus when application progresses, it normally goes through a feasibility study \& risk analysis.

\section{System Architecture and Use}

\section{Case Diagram}

The present system consists of two module: Doctor and Patient. The patient will have to register into the application for the first time. On registering, the patient will receive a username and password. The patient can use this username and password for logging into the app each time he uses it. After logging in, after successful log in, the system will display a welcome page with three functionalities and the user is required to select any displayed functionality. When the user wants to make an appointment and he/she knows the name of the doctor, the user can select an appointment by day. The patient will have to select a filtration type. The filtration is done on two bases: Area wise and Specialty wise. After selecting the filtration type, the doctors list will be displayed. The patient can select any particular doctor and view his profile. Also the patient can view the doctor's schedule and look for an appointment according to his convenience. The patient will then send a request for appointment. The doctor can either accept the appointment or reject it. The database will get updated accordingly and the patient will get a confirmation message. The add-on to this system is that the patient will receive a notification before the actual appointment. This will be very useful in case the patient tends to forget the appointment.
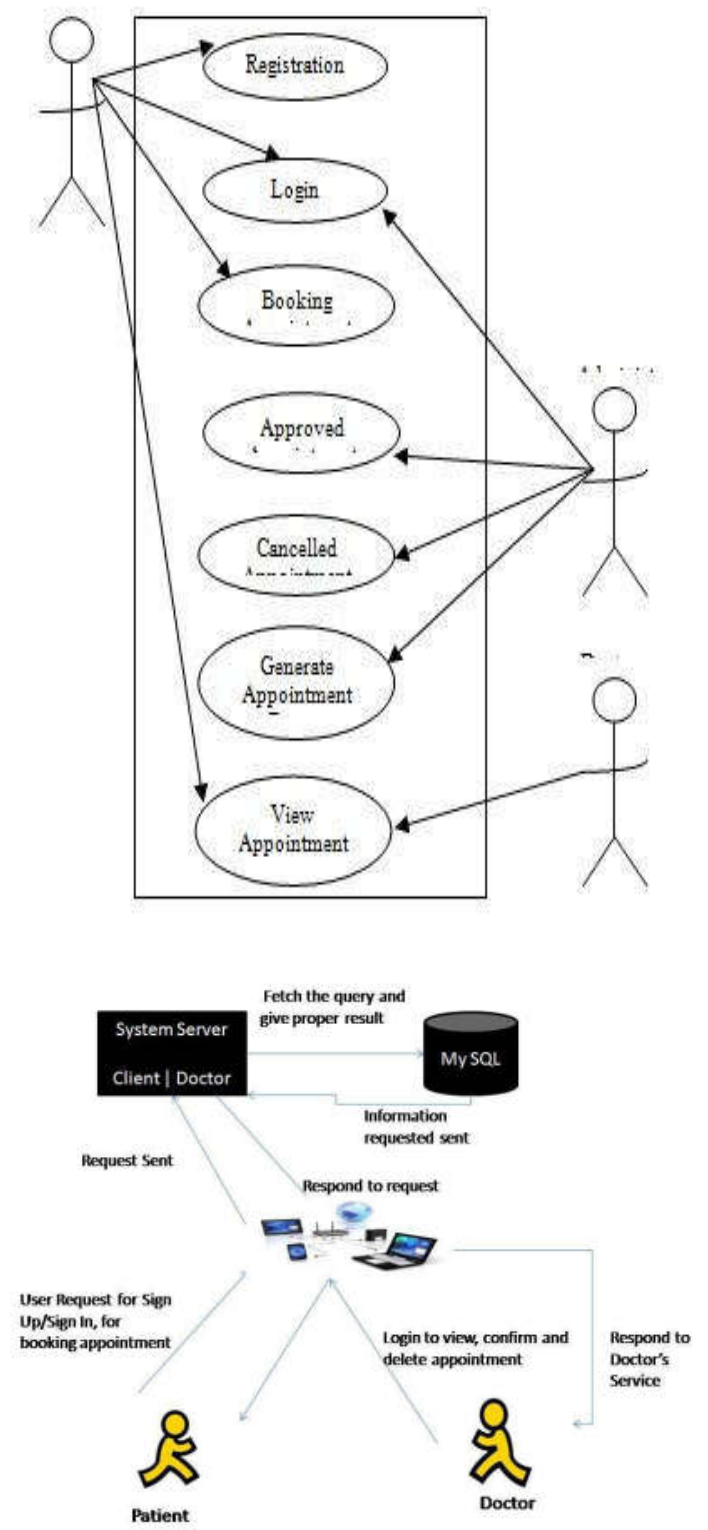

Fig use case diagram

\section{RESULT AND ADVANTAGES}

The application is a freeware, user friendly and easily accessible. Patients will have 24-hours-a-day access to appointments online, but you will still maintain control over which appointments are shown as available. Also it will reduce the effort and paperwork of both patient as well as 
doctor. Improves communication with patients- you have the option of emailing patients information about their past or upcoming appointment. The android application will prove very beneficial to doctors and patients. It saves precious time both of them. Doctors need a smooth tide of patients when attending the scheduled patients.

\section{CONCLUSION}

Scheduling appointments appropriately and resourcefully is vital to the smooth process of the hospitals' service delivery. Working in the new era of science and technology, people have the slight patience for waiting in the queue at the hospitals. This system aims to simplify the task of the patient and the doctor. It will make patients more relaxed as they do not have to stand in a long queue to fix their appointment and also book an appointment according to their choice in a more convenient way. Doctors need a smooth tide of patients when attending the scheduled patients. Doctors need not worry about managing their appointment. Though you are not going to clinic for taking an appointment, your appointment gets booked from anywhere and however you want. This helps to save the time of patient. Also the patient can get the doctor of his choice through various filters used in the application. The doctor is also able to view his day to day appointment list which makes it easier for him to plan his schedule. This application will help to optimize the work of patient and doctor.

\section{References}

1. Mark L.Murphy, "The Busy Coder's Guide to Android Development," United States of America, Commons Ware, LLC, 2008.

2. West, D., How mobile devices are transforming healthcare. Issues in technology innovation, 2012. 18(1): p. 1-11.

3. Choudhari, S., et al., Android Application for

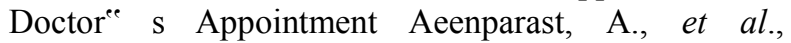
Reducing Outpatient Waiting Time: A Simulation Modeling Approach. Iran Red Crescent Med J, 2013. 15(9): p. 865-869.

4. Frank Sposaro and Gary Tyson, "iFall: An android application for fall monitoring and response", 31st Annual International Conference of the IEEE Engineering in Medicine and Biology Society, 1:6119-22, 2009.

5. Healthcare IT News, "Electronic Medical Record (EMR)", Internet: www.healthcareitnews.com/ directory/electr onic-medical-record-emr, 2014 [June $18,2014]$.

6. R. Alnanih, T. Radhakrishman, O. Ormandjieva, Characterizing Context for Mobile user Interfaces in Health Care Applications, SciVerse ScienceDirect, vol. 10, pp. 1086-1093, June 2012.
7. K. Miller and S. Suresh, "Applications of Policy based Agents in Wireless Body Sensor Mesh Networks for Patient Health Monitoring," International Journal of eHealth and Medical communications, vol. 2, no. 2, pp. 24-45

8. T. Edwards and S. Suresh, "Applications of Agents in Hospital Search and Appointment System," International Journal of E-services and Mobile Applications, vol. 3, no. 4, pp. 57-81.

9. D. Gupta and B. Denton, "Appointment scheduling in health care: challenges and opportunities," [Online]. Available: http://www.accessmylibrary.com/coms2/su mmary 028635370606_IT M

10. http://www.androidzoom.com/android_app lications/health_and_fitness/blood-pressure-control nln.html

11. http://www.developer.android.com

12. Dimitris Tychalas, "Planning and Development of an Electronic Health Record Client based on the Android Platform," Panhellenic Conference on Information, 3-6, 2010(14).

13. West, D., How mobile devices are transforming healthcare. Issues in technology innovation, 2012. 18(1): p. 1-11.

14. Aeenparast, A., et al., Reducing Outpatient Waiting Time: A Simulation Modeling Approach. Iran Red Crescent Med J, 2013. 15(9): p. 865-869.

15. Symey, Y., S. Sankaranarayanan, and S.N. binti Sait, Application of Smart Technologies for Mobile Patient Appointment System. International Journal, 2013. 2(4).

16. Mey, Y.S. and S. Sankaranarayanan. Near field communication based patient appointment. in Cloud \& Ubiquitous Computing \& Emerging Technologies (CUBE), 2013 International Conference on. 2013. IEEE.

17. Bhat, S., et al., Intelligent Scheduling in Health Care Domain. International Journal of Computer Science Issues (IJCSI), 2011. 8(5).

18. Hylton III, A. and S. Sankaranarayanan, Application of Intelligent Agents in Hospital Appointment Scheduling System. International Journal of Computer Theory and Engineering, 2012. 4(4): p. 625-630.

19. Van der Meer G, Loock JW, Why Patients Miss Follow-up Appointments: A Prospective ControlMatched Study, East African journal of public health, 5(3), p. 154- 156, 2008.

\section{Please cite this article in press as:}

Satyam Singh and Rahul Kumar (2017), 'Dr. Appointment And Communication Android Application', International Journal of Current Advanced Research, 6(3), pp. 2941-2943.

http://dx.doi.org/10.24327/ijcar.2017. 2943.0148 